\title{
A Time Frame for Testing Negative for SARS-COV2 in People with Obesity
}

\author{
Dror Dicker ${ }^{a}$ b Shaul Lev ${ }^{c}$ Tamar Gottesman $^{d}$ Tatiana Kournos $^{a}$ \\ Maya Dotan ${ }^{a}$ Nina Ashorov ${ }^{a}$ Dana Marcoviciua Rachel Golan ${ }^{\text {e }}$ \\ aDepartment of Internal Medicine D, Hasharon Hospital, Rabin Medical Center,

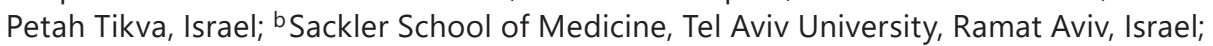 \\ 'Intensive Care Unit, Hasharon Hospital, Rabin Medical Center, Petah Tikva, Israel; \\ dDepartment of Infectious Diseases and Infection Control Service, Hasharon Hospital, \\ Rabin Medical Center, Petah Tikva, Israel; e Department of Public Health, Faculty of \\ Health Sciences, Ben-Gurion University of the Negev, Beer-Sheva, Israel
}

\author{
Keywords \\ Obesity · Overweight · SARS-COV2
}

\section{Abstract}

Objective: Obesity is a major risk factor for becoming seriously ill with the 2019 novel coronavirus (COVID-19). One difficulty faced by clinicians and by patients is the unknown time frame of hospitalization until discharge of symptomatic patients. Methods: We followed 34 patients with laboratory-confirmed COVID-19 infection who recovered from the infection. All diagnoses were given using semi-quantitative RT-PCR on nasopharyngeal swabs. Envelope protein gene (E), RNA-dependent RNA polymerase gene (RdRP), and nucleocapsid gene (N) were measured by RT-PCR. Weight was measured and height was self-reported. Results: Mean \pm SD age was $51.8 \pm 16.7$ years. Mean \pm SD body mass index (BMI) was $27.4 \pm 4.7 \mathrm{~kg} /$ $\mathrm{m}^{2}$. 26\% (9/34) had obesity, with BMI above $30 \mathrm{~kg} / \mathrm{m}^{2}$. Fifteen patients had BMI between 25 and $29.9 \mathrm{~kg} / \mathrm{m}^{2}$. The mean length of hospital stay was longer for those with a BMI $>25 \mathrm{~kg} / \mathrm{m}^{2}$ $(n=24)$ than for those with a normal BMI (19.2 vs. 16.0 days, $p=0.08)$. Comparing people with obesity (BMI $>30 \mathrm{~kg} / \mathrm{m}^{2}$ or above) to those without obesity, the difference was larger (20.6 vs. 16.0 days, $p=0.06)$. A trend for correlation between body weight and the time to negative detection of RdRp gene was found ( $r=0.33, p=0.09$ ). Conclusions: Our results highlight the need for priority of early detection and testing, and early therapy for people with obesity and COVID-19 infections. 


\section{Introduction}

The World Health Organization (WHO) has declared the 2019 novel coronavirus (COVID-19) epidemic as a public health emergency of international concern [1] and considers noncommunicable diseases, such as obesity, a major risk factor for becoming seriously ill with COVID-19 [2]. A study by the UK Intensive Care National Audit and Research Centre indicates that two thirds of people who developed serious or fatal COVID-19-related complications were overweight or had obesity [3]. Other studies have reported large proportions of patients with overweight and obesity among those admitted with COVID-19 [4-8]. These support the possibility that obesity may be an independent risk factor for complications of COVID-19.

During and after the 2009 influenza A/H1N1 pandemic, body mass index (BMI) was recognized as an independent risk factor, as evident by increased disease severity, hospitalization, risk of spreading the disease, and death [9].

We previously described the time frame for ending the isolation of patients affected by COVID-19 [10]. The aim of our current study was to compare the duration for ending the isolation period of COVID-19 between people with and without obesity. We describe the dynamics of the disease that paralleled changes in the viral load, based on SARS-CoV-2 RNA detection during March and April 2020.

\section{Materials and Methods}

We followed 34 patients with laboratory-confirmed COVID-19 infection who were treated following a diagnosis of COVID-19, and who recovered from the infection during March and April 2020. All the diagnoses were given using semi-quantitative RT-PCR on nasopharyngeal swabs. We assessed patterns of the clinical disease and viral load from nasopharyngeal samples that were obtained once daily for the first 3 days following hospital admission, and once every 2 or 3 days subsequently until discharge. Clinical specimens for COVID-19 diagnostic testing were obtained in accordance with the US Centers for Disease Control and Prevention (CDC) guidelines. Nasopharyngeal samples were tested with the assay developed by the CDC [11] and based on the WHO standard. All the samples were refrigerated and shipped to the Rabin Medical Center, where RNA extraction, RT-PCR, and the virus isolation and titration procedures were performed. Envelope protein gene (E), RNA-dependent RNA polymerase gene (RdRP), and nucleocapsid $(\mathrm{N})$ gene were measured by RT-PCR (AllplexTM 2019-nCoV) $[12,13]$. If one target was detected, the assay was reported as positive. Recovery was defined as two negative measurements for all three genes. Weight was measured upon admission, and height was self-reported. Here we describe the days to recovery from the first day of appearance of symptoms. The study was approved by the institutional review board of the Rabin Medical Center.

\section{Statistical Analysis}

Descriptive statistics were used to summarize the data. The results are reported as means and standard deviations, and ranges. Categorical variables were summarized as counts and percentages. We used the $\chi^{2}$ and Fisher's exact test to study differences between persons with and without hypertension, with and without type 2 diabetes, and between those with and without elevated body temperature $\left(\geq 38^{\circ}\right)$ during hospitalization. BMI was analyzed both as a continuous variable and by categories (BMI $<25$, BMI $25-29.9$, BMI $>30 \mathrm{~kg} / \mathrm{m}^{2}$ ). We used Student's $t$ test and ANOVA, respectively, in the analysis of BMI. For our analyses, $p$ values are shown. All the analyses were performed with IBM SPSS statistics.

\section{Karger's}


Table 1. Characteristics of the study population by BMI category

\begin{tabular}{lcccc}
\hline Variable & $\begin{array}{l}\mathrm{BMI}<25 \mathrm{~kg} / \mathrm{m}^{2} \\
(n=16)\end{array}$ & $\begin{array}{l}\mathrm{BMI}=25-29.9 \mathrm{~kg} / \mathrm{m}^{2} \\
(n=25)\end{array}$ & $\begin{array}{l}\mathrm{BMI}>30 \mathrm{~kg} / \mathrm{m}^{2} \\
(n=19)\end{array}$ & $p$ value \\
\hline BMI, mean $\pm \mathrm{SD}, \mathrm{kg} / \mathrm{m}^{2}$ & $22.3 \pm 2.0$ & $27.1 \pm 1.5$ & $33.4 \pm 3.1$ & $<0.001$ \\
Age mean $\pm \mathrm{SD}$, years & $48.0 \pm 20.1$ & $58.2 \pm 13.9$ & $52.4 \pm 18.7$ & 0.4 \\
Male, $n(\%)$ & $8(50)$ & $18(72)$ & $14(74)$ & 0.3 \\
$\begin{array}{l}\text { Body temperature above } 38^{\circ} \mathrm{C} \text { during } \\
\quad\end{array}$ & $13(81)$ & $18(72)$ & $12(63)$ & 0.5 \\
hospitalization, $n$ (\%) & $6(37)$ & $13(52)$ & $11(58)$ & 0.5 \\
Dyslipidemia, $n(\%)$ & $2(12)$ & $7(28)$ & $6(32)$ & 0.2 \\
Type 2 diabetes, $n(\%)$ & $3(19)$ & $12(48)$ & $8(42)$ & 0.2 \\
Hypertension, $n$ (\%) & $13.8 \pm 5.3$ & $18.4 \pm 4.6$ & $17.8 \pm 7.0$ & 0.07 \\
\hline
\end{tabular}

BMI, body mass index.

Fig. 1. The number of days until a negative SARS-COV2 result, by BMI category. 0: BMI $<25 \mathrm{~kg} / \mathrm{m}^{2}$; 1: $\mathrm{BMI}=25-29.9 \mathrm{~kg} / \mathrm{m}^{2} ; 2: \mathrm{BMI}$ $<30 \mathrm{~kg} / \mathrm{m}^{2}$.

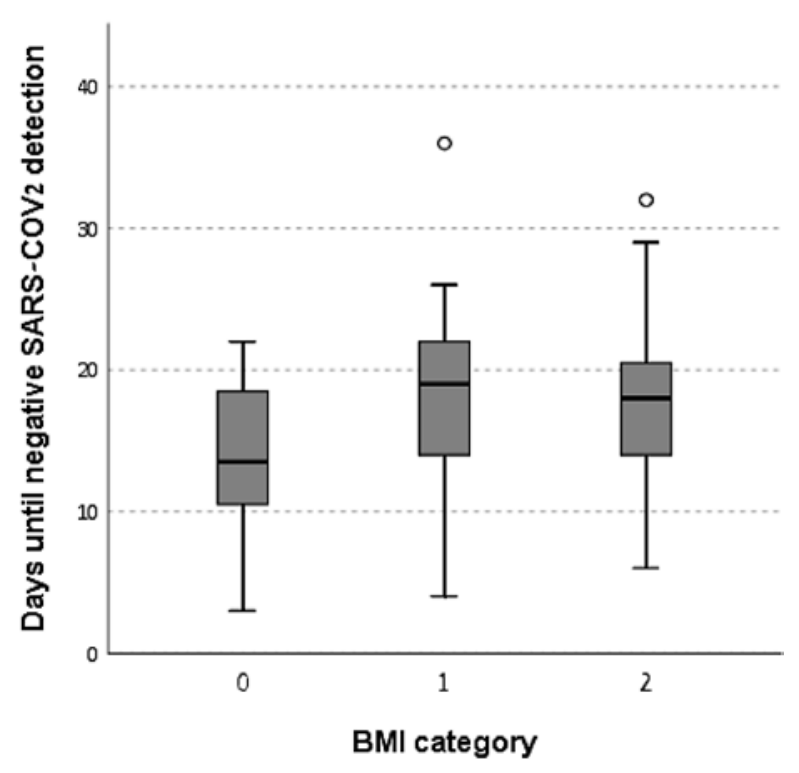

\section{Results}

The population consisted of 12 women and 22 men. Baseline characteristics of the study population by BMI group are described in Table 1 . The mean \pm SD age was $51.8 \pm 16.7$ years (range 17-81 years). The mean \pm SD BMI was $27.4 \pm 4.7 \mathrm{~kg} / \mathrm{m}^{2} .26 \%(9 / 34)$ of this cohort had obesity, with a BMI above $30 \mathrm{~kg} / \mathrm{m}^{2}$. Fifteen patients had BMI in the range of $25-29.9 \mathrm{~kg} / \mathrm{m}^{2}$. BMI distribution was similar among men and women. Twenty-four (71\%) had a body temperature above $38^{\circ} \mathrm{C}$ on admission, 13 (38\%) had hypertension, 9 (26\%) had type 2 diabetes, 18 (53\%) had dyslipidemia, and 4 were current smokers. Among the 9 patients with type 2 diabetes, 8 had a BMI above $25 \mathrm{~kg} / \mathrm{m}^{2}$. The mean time to discharge was 18.3 days, the range was 8-29 days. The mean time for a negative detection of gene E was 15 days, for gene RdRp 15.8 days, and for gene $\mathrm{N} 17.7$ days. Figure 1 describes the number of days until a complete negative result (negative detection of all three genes) according to BMI category. The mean length of hospital stay was longer for those with BMI of $25 \mathrm{~kg} / \mathrm{m}^{2}$ or above $(n=24)$ than for those with a normal BMI (19.2 days vs. 16.0 days, $p=0.08)$. Comparing people with obesity 
(BMI $>30 \mathrm{~kg} / \mathrm{m}^{2}$ or above) to those without obesity, the difference was larger (20.6 vs. 16.0 days, $p=0.06$ ). A trend for correlation between body weight and BMI with the time to negative detection of gene RdRp was found ( $r=0.33, p=0.09 ; r=0.31, p=0.12$, receptively). This trend was not found between weight and the other genes.

The mean length of hospital stay was longer for patients who presented with a body temperature above $38^{\circ} \mathrm{C}$ during hospitalization $(n=24)$ than for those who did not have an elevated body temperature (19.0 vs. 16.4 days, $p=0.1$ ). However, we found no correlation between elevated BMI and body temperature during hospitalization. The mean length of hospital stay in patients with hypertension was 19.5 days compared to 17.5 days in patients without hypertension $(p=0.2)$. Mean hospital stay was longer in patients with type 2 diabetes than in patients without type 2 diabetes (20.7 vs. 17.4 days, $p=0.08$ ).

\section{Discussion}

Although data are scarce, accumulating evidence suggests an increased risk for developing complications of COVID-19 among people with obesity. Several mechanisms have been proposed to describe this relation. First, obesity is associated with decreased pulmonary function including decreased expiratory reserve volume and respiratory system compliance [8]. Second, increased inflammatory cytokines associated with lowgrade inflammation of obesity may contribute to the "cytokine storm" of COVID-19 that increases morbidity and mortality associated with obesity [14]. Third, people with obesity have decreased immunity. An impact of obesity on immunity and pathogen defense has been shown, thus highlighting the disruption of lymphoid tissue structure and shifts in leukocyte populations and inflammatory phenotypes. In addition to chronic disease progression, these changes also reflect immunity from infection and vaccine efficacy [15]. Lastly, adipose tissue is rich in ACE2 receptor, which is the SARS-COV2 port of entry to the human cell $[16,17]$. The higher number of adipocytes in people with obesity can lead to greater viral load and prolonged viremia.

Our finding of prolonged viral clearance may also support the relation between obesity and the risk of complications of COVID-19. The positive correlation of body weight with time to negative detection of gene RdRp suggests a larger viral load in people with obesity. As shown during the $2009 \mathrm{H} 1 \mathrm{~N} 1$ influenza A virus pandemic, adults with obesity had delayed and blunted antiviral responses to influenza virus infection, experiencing poorer recovery from the disease. Furthermore, the efficacy of antivirals and vaccines was reduced. Honce and Schultz-Cherry [18] showed that both the amount of viral RNA shed and the duration of positive samples for H1N1 virus, as determined by RT-PCR, were increased in adults with obesity compared to average-weight adults. This suggests that obesity may also play a role in changing the viral life cycle, thus complementing the already weakened immune response and leading to severe pathogenesis. If this phase is similar for COVID-19, our findings emphasize the importance of longer social distancing for people with obesity affected by COVID-19. This is to ensure that they are fully free from the virus and therefore not contagious.

Our results also highlight the need for increased attentiveness, priority in early detection and testing, and early therapy for people with obesity and COVID-19 infections. Stakeholders should consider reducing the threshold for virus testing in individuals with obesity. Also, once vaccination is available, people with obesity should be encouraged to be vaccinated and treated as an at-risk population, similar to other at-risk populations such as the elderly.

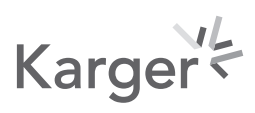




\section{Statement of Ethics}

The study protocol was approved by the Rabin Medical Center committee on human research (\# 0353-20). A written informed consent was waived by the committee.

\section{Conflict of Interest Statement}

The authors declare no conflict of interest.

\section{Funding Sources}

None.

\section{Author Contributions}

D.D.: conception of the work and interpretation of data, wrote the paper; S.L., T.G., D.M., N.A.: interpretation of the data, revised the paper; T.K. and M.D.: data acquisition, revised the paper; R.G.: data analysis, interpretation of data, wrote the paper. All authors gave final approval of the version to be published and agree to be accountable for all aspects of the work in ensuring that questions related to the accuracy or integrity of any part of the work are appropriately investigated and resolved.

\section{References}

1 Sohrabi C, Alsafi Z, O’Neill N, Khan M, Kerwan A, Al-Jabir A, et al. World Health Organization declares global emergency: A review of the 2019 novel coronavirus (COVID-19). Int J Surg. 2020 Feb;76:71-6.

2 Ryan DH, Ravussin E, Heymsfield S. COVID 19 and the Patient with Obesity - The Editors Speak Out. Obesity (Silver Spring). 2020 May;28(5):847.

3 ICNARC. Report on 196 patients critically ill with COVID-19. Available from: https://www.icnarc.org/About/ Latest-News/2020/03/22/Report-On-196-Patients-Critically-Ill-With-Covid-19.

4 Goyal P, Choi JJ, Pinheiro LC, Schenck EJ, Chen R, Jabri A, et al. Clinical Characteristics of Covid-19 in New York City. N Engl J Med. 2020 Jun;382(24):2372-4.

5 Gandhi RT, Lynch JB, Del Rio C. Mild or Moderate Covid-19. N Engl J Med. 2020 Apr;NEJMcp2009249.

6 Grasselli G, Zangrillo A, Zanella A, Antonelli M, Cabrini L, Castelli A, et al.; COVID-19 Lombardy ICU Network. Baseline Characteristics and Outcomes of 1,591 Patients Infected With SARS-CoV-2 Admitted to ICUs of the Lombardy Region, Italy. JAMA. 2020 Apr;323(16):1574-81.

7 Simonnet A, Chetboun M, Poissy J, Raverdy V, Noulette J, Duhamel A, et al.; LICORN and the Lille COVID-19 and Obesity study group. High prevalence of obesity in severe acute respiratory syndrome coronavirus-2 (SARS-CoV-2) requiring invasive mechanical ventilation. Obesity (Silver Spring). 2020 Jul;28(7): 1195-9.

8 Dietz W, Santos-Burgoa C. Obesity and its Implications for COVID-19 Mortality. Obesity (Silver Spring). 2020 Jun;28(6):1005.

9 Louie JK, Acosta M, Winter K, Jean C, Gavali S, Schechter R, et al.; California Pandemic (H1N1) Working Group. Factors associated with death or hospitalization due to pandemic 2009 influenza A(H1N1) infection in California. JAMA. 2009 Nov;302(17):1896-902.

10 Dicker D, Kournos T, Marcoviciu D, Golan R. Do we know when to end isolation of persons affected with COVID-19? Eur J Intern Med. 2020 Jul;77:144-6.

11 Centers for Disease Control and Prevention. Coronavirus disease 2019 (COVID-19). 2020. Available from: https://www.cdc.gov/coronavirus/2019-ncov/lab/rt-pcr-detection-instructions.html.

12 World Health Organization. Novel coronavirus - China. January 12, 2020. Available from: http://www.who. int/csr/don/12-january-2020-novel-coronavirus-china/en/.

13 Corman VM, Landt O, Kaiser M, Molenkamp R, Meijer A, Chu DK, et al. Detection of 2019 novel coronavirus (2019-nCoV) by real-time RT-PCR. Euro Surveill. 2020 Jan;25(3).

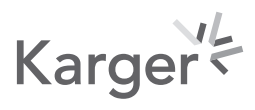


14 GBD 2015 Obesity Collaborators. Afshin A, Forouzanfar MH. Health effects of overweight and obesity in 195 countries over 25 years. N Engl J Med. 2017;377:13-27.

15 Andersen CJ, Murphy KE, Fernandez ML. Impact of obesity and metabolic syndrome on immunity. Adv Nutr. 2016 Jan;7(1):66-75.

16 Malavazos AE, Corsi Romanelli MM, Bandera F, Iacobellis G. Targeting the Adipose Tissue in COVID-19. Obesity (Silver Spring). 2020 Jul;28(7):1178-9.

17 Sattar N, McInnes IB, McMurray JJ. Obesity a risk factor for severe COVID-19 infection: multiple potential mechanisms. Circulation. 2020 Jul;142(1):4-6.

18 Honce R, Schultz-Cherry S. Impact of obesity on influenza A virus pathogenesis, immune response, and evolution. Front Immunol. 2019 May; 10:1071. 